\title{
AU1 3D Printing of Structured Nanotitania Catalysts: A Novel Binder-Free and Low-Temperature Chemical Sintering Method
}

\author{
AU2 Ander Elkoro ${ }^{1,2}$ and Ignasi Casanova ${ }^{1-3}$
}

\begin{abstract}
Pure titania nanoparticles were used successfully to manufacture 3D prints of monoliths using a high-precision paste extruder and a novel binder-free, low-temperature chemical sintering method. Nanoparticles become bonded to each other through formation of oxygen bridges by acid-induced dehydration of surface hydroxyl groups. Two different monolith designs were printed by additive superposition of paste filaments extruded through a 580- $\mu$ m-diameter tip. Prints are self-supporting and chemically stable after a thermal post-treatment at $150^{\circ} \mathrm{C}$. Such thermal processing does not affect the crystal structure of the phases that constitute the nanoparticles, and the original high anatase content is maintained. The 3D-printed monolith structures show a high photocatalytic activity, as evidenced by the rates of gas-phase acetaldehyde removal.
\end{abstract}

Keywords: 3D printing, direct ink writing, $\mathrm{TiO}_{2}$, nanoparticles, photocatalysis, chemical sintering

\section{Introduction}

AdDITIVE MANUFACTURING (AM), or 3D printing (3DP), is a group of technologies based on layer-by-layer deposition of material to build 3D structures. Since its development in the 1980s, techniques and usable materials have been increasing fast, from polymers to metals, ceramics, or food. Furthermore, titanium dioxide $\left(\mathrm{TiO}_{2}\right)$ is a well-known photocatalyst capable of generating free radical species in both aqueous and organic solvents and in the presence of oxygen on irradiation, as first demonstrated by Fujishima and Honda. ${ }^{1}$ The band gap of $\mathrm{TiO}_{2}$ corresponds to ultraviolet (UV) wavelengths. On absorbance of light, electrons in the conduction band can form superoxide radicals $\left(\mathrm{O}_{2}^{-}\right)$from adsorbed oxygen, and holes in the valence band can form hydroxyl radicals $(-\mathrm{OH})$ from water.

Stereolithography (SLA) and fused deposition modeling $(\mathrm{FDM})$ are $\mathrm{AM}$ techniques that require the use of polymers. The first one is based on selective polymerization on exposure to light. ${ }^{2}$ In FDM, the model or part is produced by extruding small beads that harden immediately to form layers, typically of a thermoplastic or metallic material. ${ }^{3}$ In both methodologies, a polymeric binder is required. This, on one hand, limits the photocatalytic activity of whatever photoactive material is supported by the binder (essentially, reducing direct exposure to light) and, on the other hand, requires a high-temperature postprocessing that reduces the surface area and hence the photocatalytic activity of the materials due to sintering and subsequent increase of the average grain size.

Direct ink writing (DIW) techniques are suitable for working without a polymer, using the ink viscous behavior or drying to maintain the printed shape. In DIW, a fluid referred to as an "ink" is extruded through a small nozzle, drawing out the shape of each layer of a predefined computer-aided design (CAD) model. Different DIW techniques include micropen writing, robocasting, ink-jet printing, and hot-melt printing. ${ }^{4}$ Duoss et al. ${ }^{5}$ developed different sol-gel inks for direct-write assembly of micropatterned oxides, one of them for $\mathrm{TiO}_{2}$. It was based on organometallic compound, which requires high temperatures $\left(>600^{\circ} \mathrm{C}\right)$ for total phase conversion. Recently, Torres Arango et al. ${ }^{6}$ developed an innovative DIW methodology to produce $\mathrm{TiO}_{2}$ films on flexible substrates with lower temperatures, assessing the effects of polymer addition on the rheological properties of Ti-organic/ $\mathrm{TiO}_{2}$ inks.

\footnotetext{
${ }^{1}$ NEMEN, Universitat Politecnica de Catalunya Institut de Tecniques Energetiques, Barcelona, Spain.

${ }^{2}$ Department of Civil and Environmental Engineering, Universitat Politecnica de Catalunya Escola Tecnica Superior d'Enginyers de Camins Canals I Ports de Barcelona, Barcelona, Spain.

${ }^{3}$ Barcelona Research Center in Multiscale Science and Engineering, Barcelona, Spain.
} 
This work further explores the concept of binder-free 3DP nanotitania monoliths for photocatalytic applications. The concept behind the proposed methodology relies on chemical sintering processes and was theorized by Kijitori et al. ${ }^{7}$ This approach is based on formation of oxygen bridges between $\mathrm{TiO}_{2}$ nanoparticles in an acidic medium at low temperatures. Park et al. ${ }^{8}$ used this approach for dye-sensitized solar cell fabrication of titania films over plastic support. Also, Li et al. ${ }^{9}$ successfully proved the chemical sintering of $\mathrm{TiO}_{2}$ nanoparticles.

In this work, chemical sintering and robocasting techniques have been combined to demonstrate the feasibility of producing isolated or supported $3 \mathrm{D}$ objects without the need of high-temperature treatment, thus substantially increasing the potential of 3D-printed monoliths for photocatalytic air purification applications.

\section{Materials and Methods}

\section{Paste preparation and 3DP}

Titanium (IV) oxide Aeroxide ${ }^{\circledR}$ P90 powder (13 nm particle size, $70-80 \%$ anatase, $20-30 \%$ rutile, specific surface $90 \mathrm{~m}^{2} / \mathrm{g}$ ) has been used as the base material for the preparation of extrudable pastes. To avoid contamination and undesired chemical reactions, only glass, polypropylene, or

AU4 PTFE containers and utensils were used.

Acid was added to water at the required concentration to obtain a solution of known $\mathrm{pH}$. The solution was put into a beaker and weighed. The corresponding amount of $\mathrm{TiO}_{2}$ nanoparticle powder was weighed and carefully added to the solution continuously until homogenization (i.e., no observable presence of aggregates) was achieved. Mixes were then introduced in a syringe, avoiding the formation of air bubbles.

A modified $\mathrm{BCN} 3 \mathrm{D}+{ }^{\circledR} 3 \mathrm{D}$ printer with a horizontal and vertical positioning accuracy of \pm 50 and $\pm 100 \mu \mathrm{m}$, respectively, was optimized for the production of the 3D structures. The maximum force exerted by the paste extruder was $125 \mathrm{~N}$.

Monolith designs were carried out with a CAD software package and exported to generate SLA files. These files were then used to create G-Code files with a slicing software package. In this step, design is transformed to layers and printing parameters are adjusted. Parametric configurations were prepared for each design and material.

The paste extruder was equipped with a polypropylene syringe and tips of $580 \mu \mathrm{m}$ in diameter. Monoliths were successfully printed over a PTFE film to prevent slippage and make post-treatment possible without manipulation of the soft paste.

\section{Chemical and mineralogical characterization}

$\mathrm{X}$-ray diffraction (XRD) characterization was carried out with a Bruker D8 Advance instrument equipped with a nineposition rotary sample changer and goniometer head with rotating capillary for powder diffraction measurements. XRD was used for the identification and quantification of crystal phases of the initial material and pastes after different posttreatments. Anatase and rutile phase fractions were calculated following the method described by Fu et al. (Eqn. 1). ${ }^{10}$ Particle size was calculated using the Scherrer method (Equation 2), which relates particle size to the width of diffraction peaks.
Equation 1. Fu et al. ${ }^{10}$ method for crystal phase analysis

$$
\% \text { Rutile }=\frac{1}{\left(\frac{A}{R} 0.884\right)+1} \cdot 100,
$$

where $\mathrm{A}$ is the area of anatase peak and $\mathrm{R}$ is the area of rutile peak. The number 0.884 is a scattering coefficient.

Equation 2. Crystal size determinations were done using the Scherrer equation.

$$
\tau=\frac{K \lambda}{\beta \cos \theta}
$$

where $\tau$ is the main particle size

$\mathrm{K}$ is a dimensionless shape factor

$\lambda$ is the $\mathrm{X}$-ray wavelength

$\beta$ is the line broadening at half-maximum intensity (FWHM) in radians

$\theta$ is the Bragg angle in degrees

Complementary phase identifications were conducted with a commercial Renishaw ${ }^{\circledR}$ inVia ${ }^{\mathrm{TM}}$ Qontor ${ }^{\circledR}$ confocal Raman microscope. The Raman setup consists of a laser $(532 \mathrm{~nm}$ with a nominal $100 \mathrm{~mW}$ output power) directed through an adapted Leica DM2700M microscope; light is collected and directed to a spectrometer with a 2400 lines $/ \mathrm{mm}$ grating. The exposure time was $0.5 \mathrm{~s}$, the laser power was adjusted to $1 \%$ of its nominal output power, and each spectrum was the result of nine accumulated scans.

A UV-visible-NIR spectrometer (Shimadzu 3600) with UV-probe software was used for photometric analysis of solids in the $300-600 \mathrm{~nm}$ range. The instrument is equipped with an ISR 3100 integrating sphere to measure diffuse reflectance and characterize the optical properties of samples.

A Zeiss Neon40Crossbeam Station equipped with field emission electron source equipment was used for standard error of the mean (SEM) analysis. Images were obtained at a constant $5 \mathrm{kV}$ acceleration potential.

Samples surfaces were analyzed with the objective of detecting interparticle bond signals, possible surface changes, and $\mathrm{TiO}_{2}$ doping as a consequence of acidic chemical sintering and their correlation with UV-Vis diffuse reflectance results. X-ray photoelectron spectroscopy (XPS) analyses were performed on an SPECS ${ }^{\mathrm{TM}}$ system equipped with an $\mathrm{Al}$ anode XR50 source operating at $150 \mathrm{~mW}$ and a Phoibos $150 \mathrm{MCD}-9$ detector. The pass energy of the hemispherical analyzer was set at $25 \mathrm{eV}$ and the energy step was set at $0.1 \mathrm{eV}$. The binding energy values were referred to the $\mathrm{C} 1 \mathrm{~s}$ peak at $284.8 \mathrm{eV}$

\section{Photocatalytic testing}

Photocatalytic testing was performed with the aim of quantifying VOCs removal capacity of 3D-printed monoliths. The photocatalytic system is composed of a synthetic air source, mass flow controller, bubbler, light source, reactor, and gas chromatograph. Experiments were carried out at atmospheric pressure and room temperature, under dynamic conditions. Synthetic air, at a flow rate of $20 \mathrm{~mL} / \mathrm{min}$, was bubbled into a saturator containing a water/acetaldehyde mixture. The gaseous mixture was directly introduced into a photoreactor consisting of two glass cylindrical parts and a rubber O-ring, to ensure the gas flow through the sample channels. Monoliths 


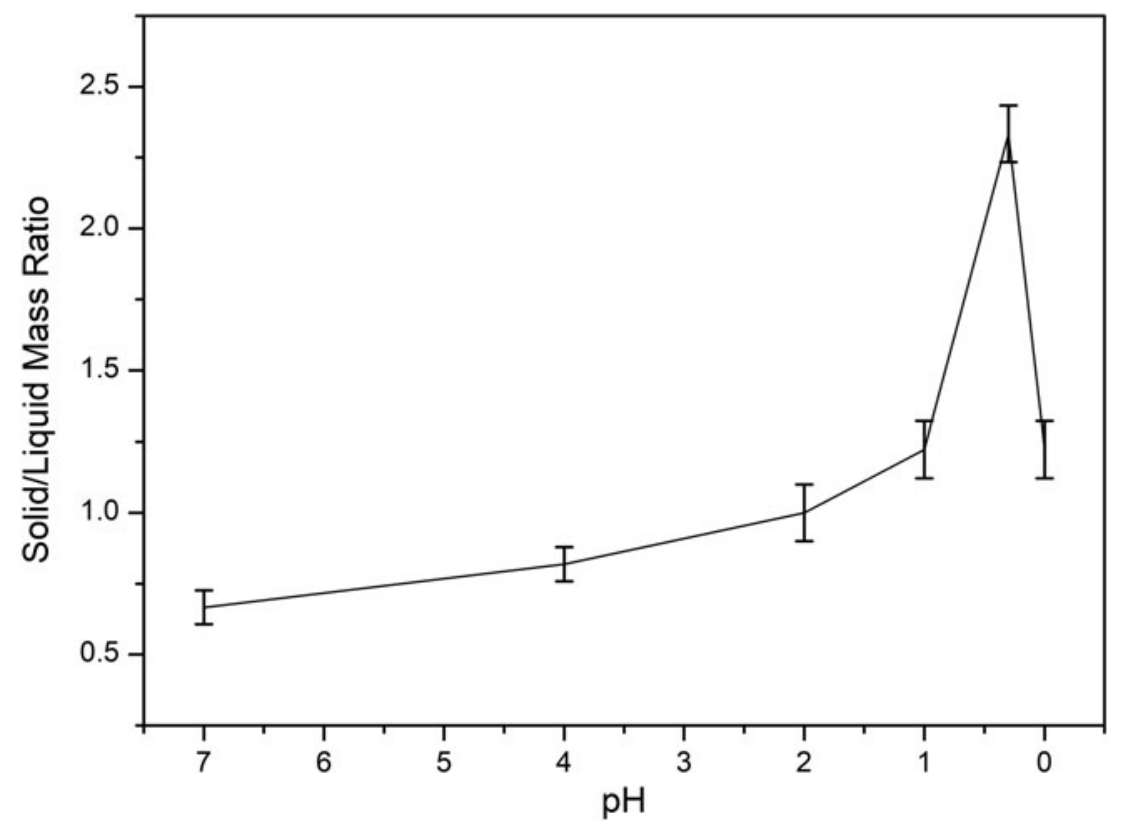

FIG. 1. pH dependence of the solid/liquid mass ratio of nanotitania pastes. Bars represent the range of mass ratios needed for efficient extrusion.

AU7 were illuminated by four UV LEDs $(365 \mathrm{~nm})$, generating an $84 \mathrm{~mW} / \mathrm{cm}^{2}$ radiation in the inlet of monoliths. The outlet of the reactor was connected to an Agilent 490 Microgas chromato-

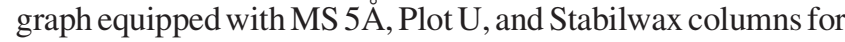
a complete and direct analysis of products every $3.5 \mathrm{~min}$.

\section{Results and Discussion}

\section{Paste behavior and 3DP}

$\mathrm{TiO}_{2}$ pastes were made adding nanoparticle powder to a water solution of $\mathrm{pH}$ ranging between 0 and 7 . To obtain printable viscosities, different solid/liquid ratios had to be used at different $\mathrm{pH}$ values of the solution. The maximum titania content is reached when the $\mathrm{pH}$ of the solution is around 0.3 (Fig. 1). The trend from $\mathrm{pH}=7$ to $\mathrm{pH}=0.3$ reflects progressive increment of the number of protons attached to the surface of the nanoparticles. The low value at $\mathrm{pH}=0$ is probably due to loss of protons due to vaporization of molecular hydrogen. Eventually, though, the $\mathrm{pH}$ decreases past the $\mathrm{pKa}$ of the Ti-OH units, which will protonate, becoming
$\left(\mathrm{Ti}-\mathrm{OH}_{2}\right)^{+}$. The positive charges cause repulsion between the nanoparticles.

In that mechanism, $\mathrm{TiO}_{2}$ nanoparticles can become interconnected when dehydration of surface hydroxyl groups occurs and oxygen bridges are formed at temperatures higher than or around $135^{\circ} \mathrm{C}$ (Fig. 2). ${ }^{7}$ The effectiveness of such mechanism was demonstrated by Li et al., ${ }^{9}$ who reported the binding of $21 \mathrm{~nm}$ spheres with $5 \mathrm{~nm}$ particles (referred to as "nano-glue"), seemingly as a result of the formation of oxygen bridges between larger and smaller titania nanoparticles. However, the proposed mechanism does not explain the observed behavior with a low $\mathrm{pH}$. Instead, observations carried out in this work favor a process analogous to the dehydration of alcohols catalyzed by acid for the formation of ether, by the formation of an oxygen bridge between two dehydrated alcohols. ${ }^{11}$

Stability of the printed materials in aqueous environments was monitored by immersion of the specimens in water for up to 2 years. Samples prepared at $\mathrm{pH} \leq 1$ and subjected to thermal treatment for $12 \mathrm{~h}$ at temperatures greater than $150^{\circ} \mathrm{C}$

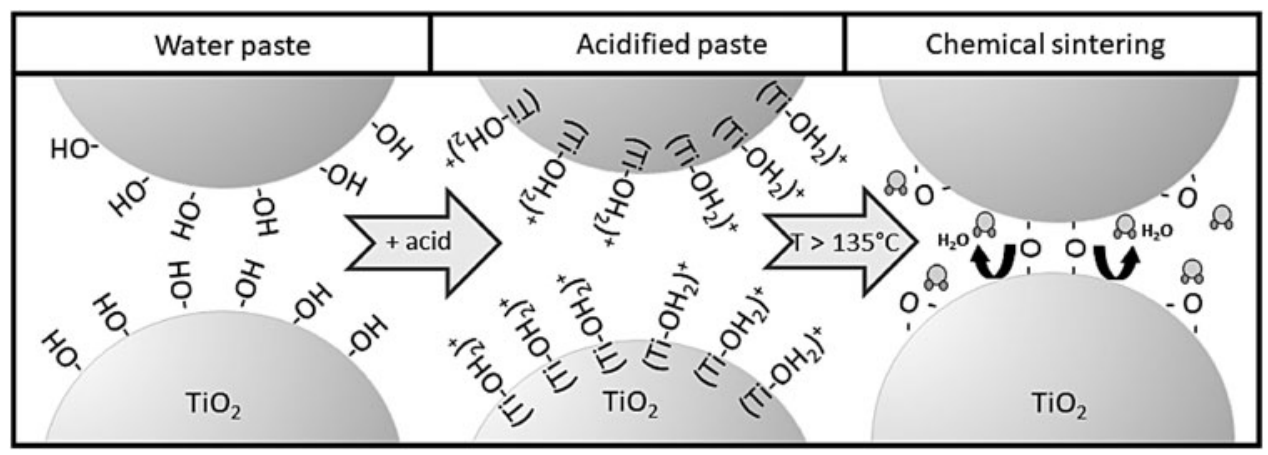

FIG. 2. Chemical sintering process, where surface hydroxyl groups incorporate acid protons forming in the surface $-\mathrm{OH}_{2}^{+}$ groups. They become dehydrated at temperatures in excess of $135^{\circ} \mathrm{C}$, releasing water and yielding to the formation of oxygen bridges. $\mathrm{TiO}_{2}$, titanium dioxide. 

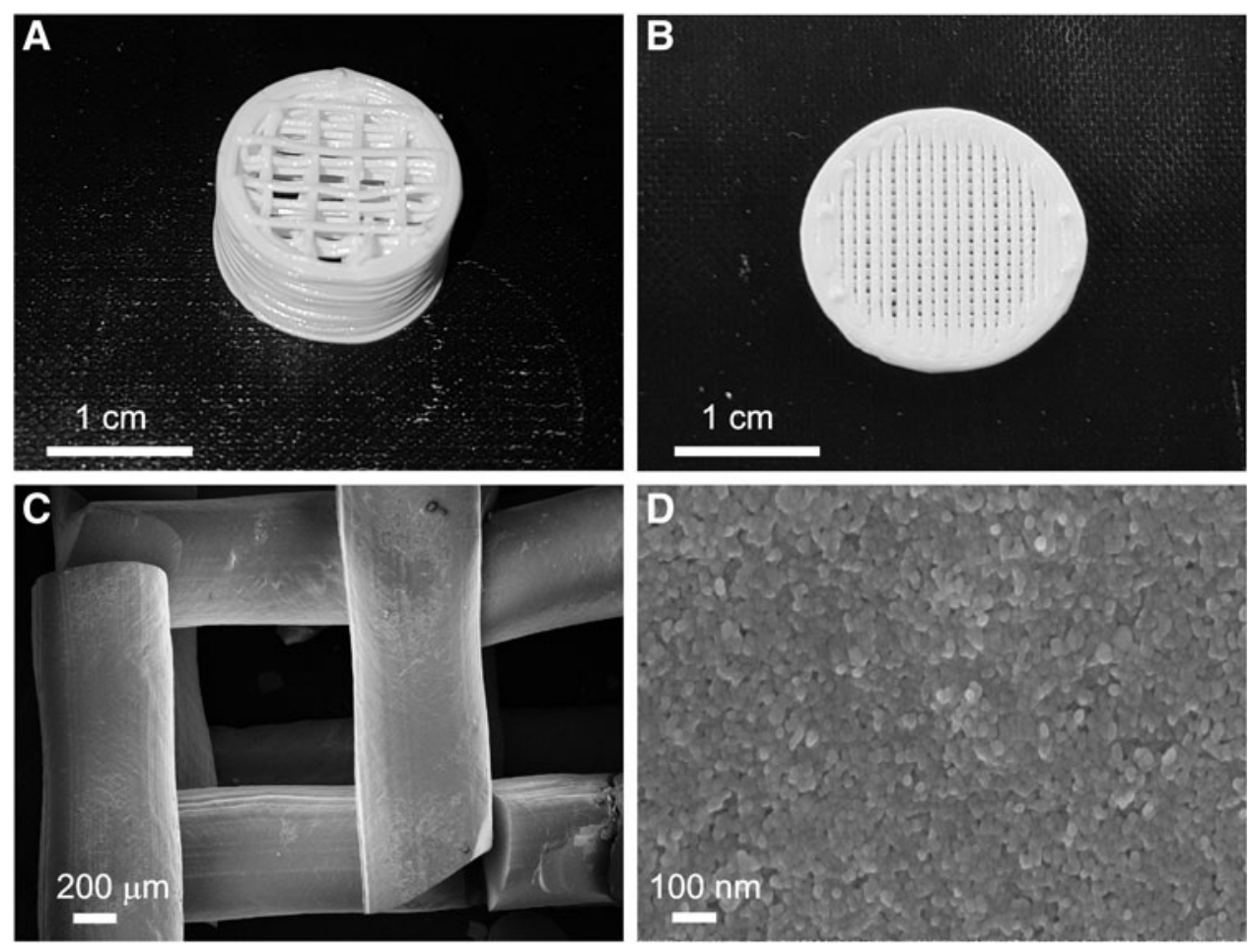

FIG. 3. 3D-printed samples. (A) Monolith (channel width $=2 \mathrm{~mm}$ ); (B) Four-layer membrane-type print (channel width $=0.5 \mathrm{~mm}$ ). Standard error of the mean images of $\mathrm{TiO}_{2}-\mathrm{HCl} 3 \mathrm{D}$ print, (C) infill of top layer, (D) filament surface.

did not show any noticeable deterioration; when the $\mathrm{pH}$ was $>2$ or the temperature of the thermal treatment was $<150^{\circ} \mathrm{C}$, cracking and eventual disaggregation were observed.

Different monolith designs were successfully 3D printed with an optimum paste dosage of $0.5 \mathrm{M}$ of $\mathrm{HCl}$ and a solid/ liquid ratio of 2. After printing, specimens were heated at $150^{\circ} \mathrm{C}$ to ensure chemical sintering. Monoliths of different shapes, heights, dimensions, and width of the internal channels were printed. Some of these are shown in Figure 3. Two different designs were tested to characterize the dependence of photocatalytic activity on the shape and size of 3D-printed titania nanoparticles. A monolith of $16 \mathrm{~mm}$ in diameter and $10 \mathrm{~mm}$ in height, with a woodpile structure and $2 \times 2 \mathrm{~mm}$ channels (Fig. 3A), was compared with a four-layer height design with $0.5 \mathrm{~mm}$ channels (Fig. 3B). Specimen design was carried out with the Slic $3 \mathrm{r}^{\mathrm{TM}}$ software package. Each design consists of two perimeter shells and a $0.5 \mathrm{~mm}$ layer. Samples of 20 and 4 layers were prepared, with a rectilinear infill of $10 \%$ and $50 \%$, and masses of 1.25 and $0.67 \mathrm{~g}$, respectively.

\section{Sample characterization}

T1 As shown in Table 1, P90 powder contains $\sim 80 \%$ anatase and $20 \%$ rutile and an average particle size of around $12 \mathrm{~nm}$. In the case of pastes, samples were prepared at $\mathrm{pH}$ values of 0 and 7 with $\mathrm{HCl}$ and deionized water, respectively. Each set of pastes was either treated at $400^{\circ} \mathrm{C}$ during $12 \mathrm{~h}$ or kept at room temperature.

Crystal phase calculations were carried out using the method described by Fu et al. ${ }^{11}$ Particle size estimation was performed with the Scherrer equation.

Samples kept at room temperature maintain almost the same phase distribution and particle size, whereas thermal treatment produces an increase in rutile content and particle size (Table 1). Acid pastes treated at $400^{\circ} \mathrm{C}$ show the largest variation, predictably because the acid content stimulates phase change and an increase of particle size. It could also be due to crystal phase heterogeneity or crystallization of the amorphous phase, as observed by Ohtani et al. ${ }^{12}$

A four-layer print with two filament perimeter and crisscrossed infill was analyzed and imaged with the SEM to detect differences between the filament surface and inner nanoparticle distribution (Fig. 3C, D).

Filament diameters were measured at different locations to evaluate shrinkage. $\mathrm{TiO}_{2}$ pastes were printed with a $580-\mu \mathrm{m}-$ diameter nozzle. Measured diameter values range between 510 and $540 \mu \mathrm{m}$, suggesting a $10 \pm 2 \%$ shrinkage, in agreement with macroscopic shrinkage measurements.

The Raman spectra of the P90 powder sample and 3Dprinted film were compared to verify that the crystal structure of titania nanoparticles remains unchanged after treatment. Both samples show five characteristic peaks for anatase at

Table 1. Crystal Phase Content and Particle Size of Paste Prepared at PH 0 and 7, and Treated AT $400^{\circ} \mathrm{C}$ Or RoOM TEMPERATURE

\begin{tabular}{lccc}
\hline Sample & \% Anatase & \% Rutile & Particle size $(\mathrm{nm})$ \\
\hline $\mathrm{TiO}_{2} \mathrm{P}-90$ & 78.7 & 21.3 & 12.2 \\
$\mathrm{pH} 0-\mathrm{RT}$ & 78.5 & 21.5 & 12.4 \\
$\mathrm{pH}-400$ & 75.9 & 24.1 & 13.4 \\
$\mathrm{pH}-\mathrm{RT}$ & 77.8 & 22.2 & 12.3 \\
$\mathrm{pH} 7-400$ & 77.7 & 22.3 & 12.7 \\
\hline
\end{tabular}

$\mathrm{TiO}_{2}$, titanium dioxide. 

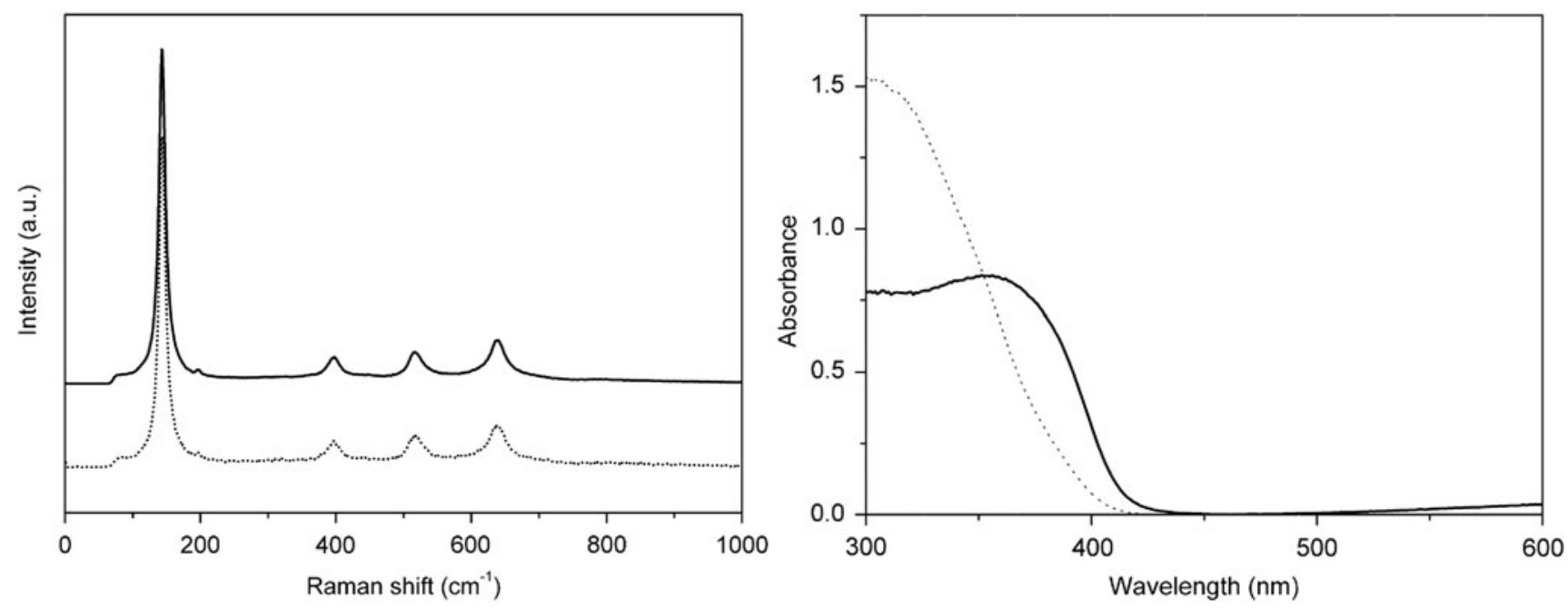

FIG. 4. Raman and ultraviolet-visible absorbance spectra of $\mathrm{P} 90$ powder (dots) and TiO2-HCl 3D print (line).

F4 144, 196, 397, 516, and 640 and none for rutile (Fig. 4). According to Kim et al., ${ }^{13}$ shifts in the Raman peak positions are associated with varying sizes of small nanoparticles. Our results agree with the reported mean particle size of the P90 material $(13 \mathrm{~nm})$.

Absorbance spectra of $\mathrm{TiO}_{2} \mathrm{P} 90$ powder and $\mathrm{TiO}_{2}-\mathrm{HCl}$ paste prints are shown in Figure 4. The band gap for the P90 sample was calculated following the Kubelka-Munk meth$\mathrm{od}^{14}$ and found to be of $3.18 \mathrm{eV}$. This value is in excellent agreement with that reported for an 80/20 mixture of anatase/ rutile $(3.2 \mathrm{eV} / 3.0 \mathrm{eV}) .^{15,16}$ The printed sample displays a clear shift to higher wavelengths, which may indicate the presence of chlorine (from $\mathrm{HCl}$ ) at the surface of the particles. Furthermore, it shows a significantly lower band gap of $2.99 \mathrm{eV}$, strongly suggesting a higher activity. These results indicate that acid treatment can be useful not only for chemical sintering but also for the enhancement of visible light absorption.

XPS was used for the chemical characterization of the surfaces of the P90 reference material and a thermally treated

F5 monolith (Fig. 5). Titanium 2p signal positions are identical for $3 \mathrm{D}$ prints and $\mathrm{P} 90,458.7 \mathrm{eV}$ for Ti $2 \mathrm{p}^{3 / 2}$. This evidences, together with XRD data, that thermal treatment has not had any significant effect on the anatase/rutile contents of the samples.

However, the $\mathrm{O}-\mathrm{H}$ bond signal $(531.9 \mathrm{eV})$ is significantly more prominent in the $\mathrm{P} 90$ sample than in the 3D print, as evidenced by the left shoulder of the main O-Ti peak (Fig. 5C). The presence of physically adsorbed water onto the P90 powder may in principle be discarded, since the ultrahigh vacuum conditions required for the XPS analysis would desorb any water adsorbed to the material. Therefore, the spectra obtained are believed to show only chemisorbed water. Although the variability of hydroxyl group contents is also related with particle size and nature of the surface, the homogeneity of the particle diameters of the P90 powder excludes this possibility, and favors the interpretation that the bonding mechanism is similar to that proposed by Kijitori et al., ${ }^{7}$ that is, through the combination of surface $\mathrm{O}-\mathrm{H}$ groups and formation of interparticle O-Ti bonds.

Chlorine has also been identified in both (untreated and treated) samples (Fig. 5B). The higher concentration of this element observed in the $\mathrm{TiO}_{2}-\mathrm{HCl} 3 \mathrm{D}$ print reveals that, even after thermal treatment at $150^{\circ} \mathrm{C}$, some $\mathrm{Cl}$ remains on the surface and is probably responsible for the observed shift toward higher wavelengths observed in the UV-Vis spectra.

\section{Photocatalytic properties}

Photocatalytic tests were started under darkness until acetaldehyde absorption was stabilized; then the UV light source was switched on. Gas flow rate and illumination conditions were maintained for $8 \mathrm{~h}$ to ensure stabilization of the photocatalytic reaction. Light was switched off and the gas flow was kept for 30 min to go back to the initial conditions.

The efficiency of the photocatalytic reaction was monitored through measurement of the concentrations of acetaldehyde (reactant) and carbon dioxide $\left(\mathrm{CO}_{2}\right)$ (product), in ppmv. As shown in Table 2, the concentrations of acetaldehyde removed (i.e., decomposition into $\mathrm{CO}_{2}$ and water) are similar in both cases and depend strongly on the amount of acetaldehyde in the gas (e.g., the conversion yields for 5000 ppmv acetaldehyde are $40-58 \%$, while for $70,000 \mathrm{ppmv}$ of acetaldehyde, the removal yields drop to about $8 \%$ but decomposed acetaldehyde grows up to $5000 \mathrm{ppmv}$ ). In any case, the activity of the four-layer membrane has been observed to be higher at all concentrations, despite its mass being approximately half of the monolith design.

\section{Conclusions}

A new method for the production of 3D-printed binder-free nanotitania monoliths has been demonstrated. Acidified aqueous pastes of $\mathrm{TiO}_{2}$ nanoparticles show a rheological behavior that permits the preparation of filaments of a few hundreds of microns in diameter, which can be arranged into a three-dimensional structure. The observed behavior strongly suggests that the consistency obtained is due to chemical sintering among the nanoparticles as a result of dehydrogenation of surface hydroxyl groups, forming oxygen bridges between adjacent nanoparticles. This process occurs at temperatures between $135^{\circ} \mathrm{C}$ and $150^{\circ} \mathrm{C}$, substantially lower than previous methods that require either crystallization of a precursor or conventional sintering above 
a
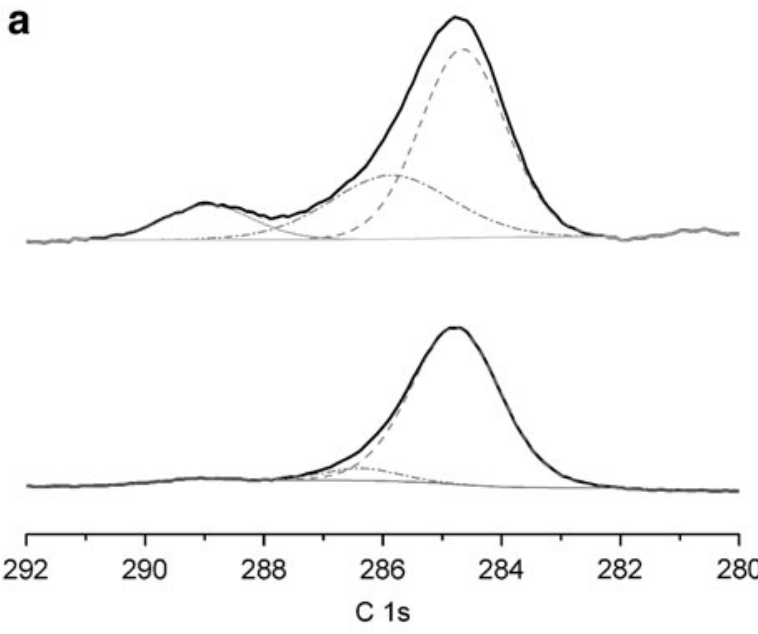

C
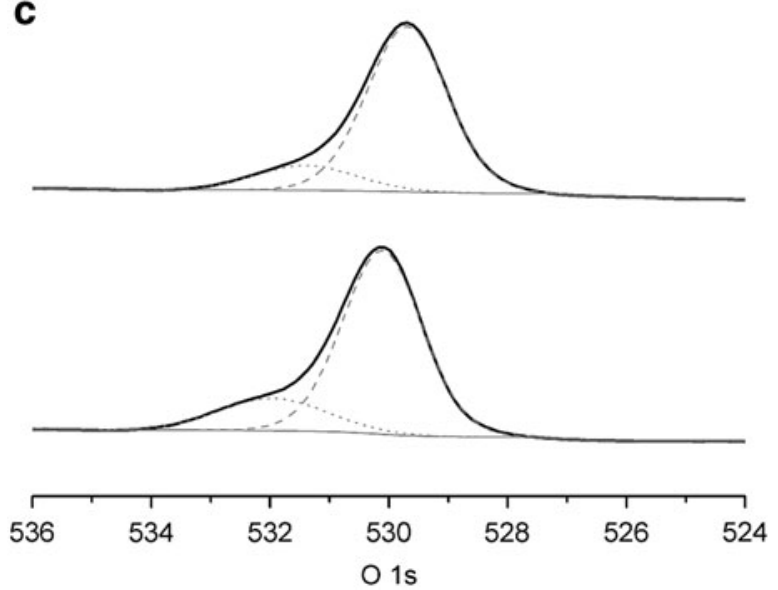

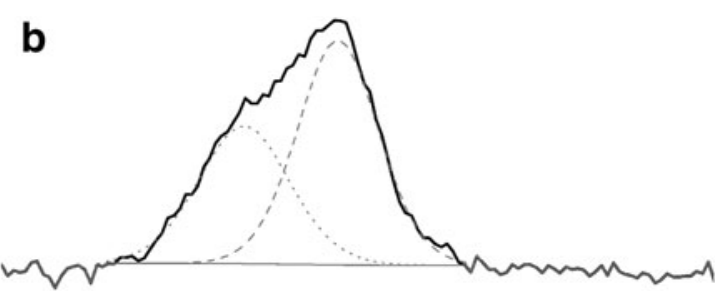

$\mathrm{TiO}_{2}-\mathrm{HCl}$

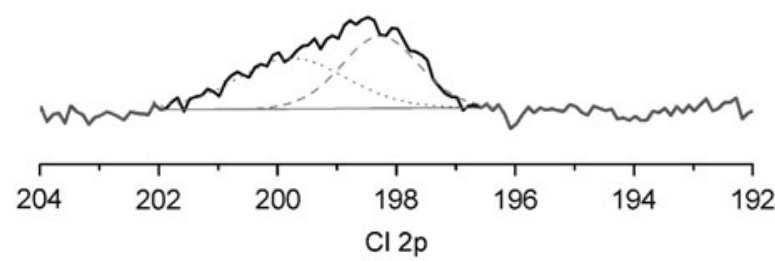

P90
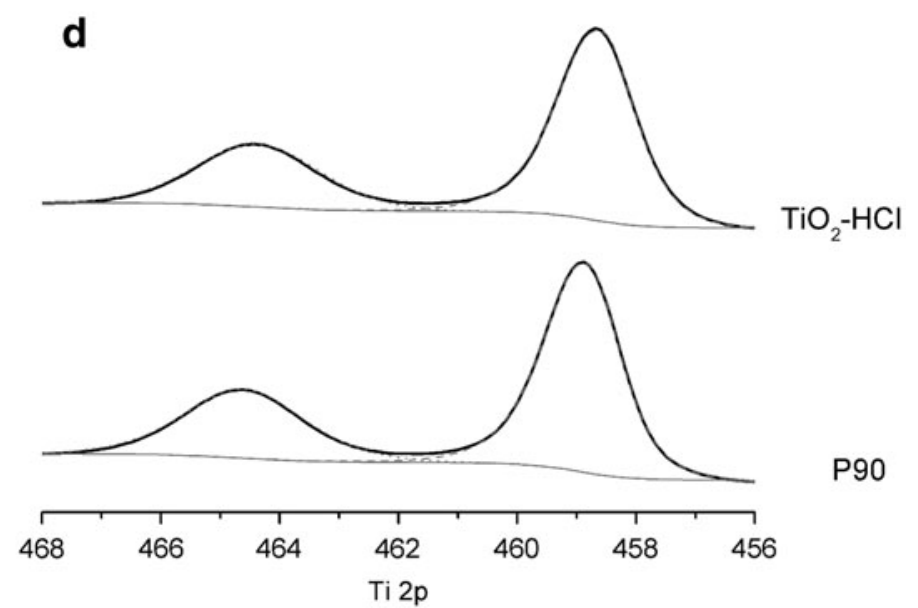

P90

FIG. 5. Deconvoluted X-ray photoelectron spectroscopy spectra of C 1s (a), Cl 2p (b), O 1s (c), and Ti 2p (d) for 3Dprinted $\mathrm{TiO}_{2}-\mathrm{HCl}$ (top) and $\mathrm{P} 90$ powder (bottom).

$450^{\circ} \mathrm{C}$, and thus avoids transformation of anatase into lessactive rutile.

The method described in this article favors the optimization of design schemes for different light sources and geometries. Utilization of binder-free monoliths maximizes the surface and interaction of light with the material, and entails a significant enhancement of photocatalytic activity.

Binder-free and low-temperature chemical sintering 3DP of $\mathrm{TiO}_{2}$ nanoparticles opens a wide range of possibilities for photocatalytic applications. The binder-free approach maximizes exposure of nanoparticles to light, and the lowtemperature sintering may be used with many different sub-

Table 2. 3D Printed Designs Acetaldehyde Removal Depending on the Initial Concentration

\begin{tabular}{|c|c|c|}
\hline & Monolith & Four-layer membrane \\
\hline $\begin{array}{c}\text { Initial } \mathrm{CH}_{3}-\mathrm{CHO} \\
\text { (ppmv) }\end{array}$ & $\begin{array}{c}\text { Removed } \\
\mathrm{CH}_{3}-\mathrm{CHO}(\text { ppmv) }\end{array}$ & $\begin{array}{c}\text { Removed } \\
\mathrm{CH}_{3}-\mathrm{CHO}(\text { ppmv) }\end{array}$ \\
\hline 5000 & 1945.5 & 2324 \\
\hline 10,000 & 3199 & 3400 \\
\hline 70,000 & 5410.5 & 5635 \\
\hline
\end{tabular}

strates. Moreover, 3DP makes the design adaptable for every application, making catalyst utilization substantially simpler for gas or water treatment.

\section{Acknowledgments}

This work was partially funded by grants 2014-DI-072 (AGAUR) and ENE2015-63969-C3-1-R (MINECO). The authors wish to express their gratitude to Guillem Masdeu (CIRCA, S.A.), Ana Robert, and Albert Casanovas for technical assistance and insightful comments. This work is part of Ander Elkoro's PhD dissertation in the Universitat Politècnica de Catalunya under the Industrial Doctorates Program supported by the Department of Economy and Knowledge of the Generalitat de Catalunya.

\section{Author Disclosure Statement}

No competing financial interests exist.

\section{References}

1. Fujishima A, Honda K. Electrochemical photolysis of water at a semiconductor electrode. Nature 1972;238:37-38. 
2. Kanehira S, Kirihara S, Miyamoto Y. Fabrication of $\mathrm{TiO}_{2}-$ $\mathrm{SiO}_{2}$ photonic crystals with diamond structure. J Am Ceram Soc 2005;88:1461-1464.

3. Skorski MR, Esenther JM, Ahmed Z, et al. The chemical, mechanical, and physical properties of 3D printed materials composed of $\mathrm{TiO}_{2}$-ABS nanocomposites. Sci Technol Adv Mater 2016;17:89-97.

4. Lewis JA. Direct ink writing of 3D functional materials. Adv Funct Mater 2006;16:2193-2204.

5. Duoss EB, Twardowski M, Lewis JA. Sol-gel inks for direct-write assembly of functional oxides. Adv Mater 2007;19:3485-3489.

6. Torres Arango MA, Valença De Andrade AS, Cipollone DT, et al. Robotic deposition of $\mathrm{TiO}_{2}$ films on flexible substrates from hybrid inks: Investigation of synthesisprocessing-microstructure-photocatalytic relationships. ACS Appl Mater Interfaces 2016;8:24659-24670.

7. Kijitori Y, Ikegami M, Miyasaka T. Highly efficient plastic dye-sensitized photoelectrodes prepared by low-temperature binder-free coating of mesoscopic titania pastes. Chem Lett 2007;36:190-191.

8. Park NG, Kim KM, Kang MG, et al. Chemical sintering of nanoparticles: A methodology for low-temperature fabrication of dye-sensitized $\mathrm{TiO}_{2}$ films. Adv Mater 2005;17:2349-2353.

9. Li Y, Lee W, Lee DK, et al. Pure anatase $\mathrm{TiO}_{2}$ "nanoglue": An inorganic binding agent to improve nanoparticle interconnections in the low-temperature sintering of dye-sensitized solar cells. Appl Phys Lett 2011;98:1-3.

10. Fu X, Clark LA, Yang Q, et al. Enhanced photocatalytic performance of titania-based binary metal oxides: $\mathrm{TiO}_{2} / \mathrm{SiO}_{2}$ and $\mathrm{TiO}_{2} / \mathrm{ZrO}_{2}$. Environ Sci Technol 1996;30:647-653.
11. Mandal S, Mandal S, Ghosh SK, et al. A review on the advancement of ether synthesis from organic solvent to water. RSC Adv 2016;6:69605-69614.

12. Ohtani B, Prieto-Mahaney OO, Li D, et al. What is degussa (Evonic) P25? Crystalline composition analysis, reconstruction from isolated pure particles and photocatalytic activity test. J Photochem Photobiol A Chem 2010;216:179-182.

13. Kim WB, Choi SH, Lee JS. Quantitative analysis of Ti-O-Si and Ti-O-Ti bonds in Ti-Si binary oxides by the linear combination of XANES. J Phys Chem B 2000;104:8670-8678.

14. Kubelka P, Munk F. An article on optics of paint layers (Engl. Übersetzung). Z Tech Phys 1931;12:593-601.

15. Takikawa H, Matsui T, Sakakibara T, et al. Properties of titanium oxide film prepared by reactive cathodic vacuum arc deposition. Thin Solid Films 1999;348:145-151.

16. Amtout A, Leonelli R. Optical properties of rutile near its fundamental band gap. Phys Rev B 1995;51:6842-6851.

Address correspondence to: Ignasi Casanova NEMEN

Universitat Politecnica de Catalunya Institut de Tecniques Energetiques Av. Eduard Maristany 10-14, Edifici C Barcelona 08028

Spain

E-mail: ignasi.casanova@upc.edu 


\section{AUTHOR QUERY FOR 3DP-2017-0164-VER9-ELKORO_1P}

AU1: Article title, authors' names, and affiliations have been taken from the provided PDF. Please check.

AU2: Please identify (highlight or circle) both authors' surnames for accurate indexing citations.

AU3: "CAD" has been defined as "computer-aided design." Please check.

AU4: Please define "PTFE."

AU5: Please expand "FWHM."

AU6: Please expand "VOCs."

AU7: Please expand "LEDs."

AU8: Please confirm the corresponding author's name and address taken from the metadata. 